\title{
Research on the Economic and Environmental Development of Shaanxi Province
}

\author{
Yaping Chen \\ Shaanxi Institute of International Trade and Commerce, Xi'an, 712046, China \\ acdm1528@126.com
}

\begin{abstract}
Keywords: Economy; Environment; Sustainable Development; Consistency Analysis; Solutions and Suggestions
\end{abstract}

\begin{abstract}
With the development of globalization and information economy, the topic of global economy in future cities has attracted more attention. At the end of 20thcentury, the United Nations World Commission on Environment and Development elaborated on sustainable development, emphasizing that the core of it is to promote the coordinated development between economy and environment. Under this context, Shanxi Province, the key province in the Western Development Plan, gradually recognized the importance of sustainable development and published a series of policies enhancing the coordinated development between economy and environment. The paper has consulted many references of national and foreign studies on this topic and combined the condition of Shaanxi's sustainable development so as to analyse the contradictions between Shaanxi's economic development and environment. Also, the paper has raised pointed solutions and suggestions by using consistency analysis.
\end{abstract}

\section{Introduction}

With the fast development of science and technology, human civilization has achieved fruitful results and the production ability has been improved in a great manner. At the same time, environmental pollution has been more severe. Environmental problems occur frequently such as Los Angeles photochemical pollution, London smog event and so on which have greatly harmed people's health and hindered the economy. In order to protect the environment, all nations begin to explore a harmonious coexistence between economy and environment, thus the concept of sustainable development emerges. In 1987, United Nations World Commission on Environment and Development defined sustainable development in a reportOur Common Future as "It satisfies the requirements of contemporaries and sustains this ability for meeting the needs of our descendants" which systematically explains the concept of sustainable development [1]. Later, Chinese government has implemented sustainable development in its economic and social development and achieved positive effects.

With the implementation of Western Development and One Belt and Road Initiative, Shaanxi's economy has achieved good results. Shaanxi even improves the development of whole western region. However, the natural environment in the Northwest of China is fragile and it lacks of water resource. The environment has been destroyed in various degrees as the economy grows. For example, the construction of energy and heavy chemical industry in Northern Shaanxi deepens the pollution of nitrogen oxide which heavily influence people's health; the increase of emission of waste gas, waste water and industrial residue by township enterprises aggravate land degradation. Recently, Shaanxi Department of Environmental Protection has issued a series of measures to promote harmonious development between economy and environment, but problems still need to be solved. This research provides a comprehensive analysis on the contradictions between economic development and environment in Shaanxi and proposes solutions and suggestions for the problems. Therefore, this research has practical significance on Shaanxi's sustainable development and the whole western region as well. 


\section{Contradictions between the Economic and Environmental Development in Shaanxi Province}

Shaanxi Province situates in the west of China and it serves as an important role in the Western Development. In recent years, its economy achieves steady growth. In 2015, according to the statistics by Shaanxi Statistics Bureau, the GDP of Shaanxi has reached 18.17186 trillion, increasing by $8 \%$ and higher than the average level. However, in the process of economic development, contradictions begin to emerge between economy and environment which seriously harm the sustainability.

\section{Natural Resources and Economic Development}

Natural resources refer to the aggregation of natural matters or energy that can be used and on which people depend. Shaanxi has plenty of natural resources, a large amount of coal resources and oil deposit but lacks of water resources. The economy is led by the secondary industry, thus there is a high demand of resources and it is harmful for the environment. For example, the development of coal industry requires a large amount of natural resources and emissions a large quantity of sulfur dioxide which badly pollute the air. In the process of economic development, it is inevitable to use natural resources, thus the contradiction between the protection of natural resources and economic development begins to emerge.

\section{Population Quality and Environment Protection}

In 2016, the census report issued by Shaanxi Statistics Bureau shows that the population of permanent residents is 30 million, increasing by 190 thousand comparing with the same period of last year. This is a reflection of the acceleration of urbanization. It also demonstrates the effect of population gathering. The increase of population provides sufficient labor force for the city's economic growth and fastens the rapid development of economy. However, the expansion of population gives burden to the protection of resources and environment. A large number of famers immigrate into urban cities, causing the increase of polluted water, garbage and wastes which would hinder the protection of urban environment. Therefore, there is contradiction between population quality and environment protection.

\section{Macro-control and Economic Growth}

Market economy plays a key role in resources allocation due to China's national condition. Chinese government has tried to transform its function and improve its macro-control policy. Shaanxi has a good geographic location which involves itself in Western Development and One Belt and Road Initiative, and its economy has greatly improved. However, the uncertainties of market economic development lead to the lack of investment in agriculture and environment protection. Sometimes the macro-control policy cannot be well implemented, thus the macro-control policy and economic growth are two problems to some extent.

\section{Consistency Analysis of Shaanxi’s Economy and Environment}

Currently, environmental protection and economic development are on opposite side. There is a trend that the faster the economy grows, the worse the environment, therefore, it is vital to analyzing the relationship between economy and environment so as to construct a good cycle system for a coordinated development and make sure the environment and economy are correlated.

\section{Environment is the Basis of Economy}

The environment provides all material resources and support for Shaanxi's economic development. This province mainly focuses on the secondary industry that requires water, energy, coals and land 
resources, which all can be provided by the environment. Thus, environment is the basis of economic development.

\section{Economic Development Changes the Environment}

Some enterprises in Shaanxi blindly pursue profits at the cost of environment. For example, paper mill will emission the polluted water into rivers to reduce its cost, and the polluted rivers poison residents' drinking water; the forests are destroyed which cause serious water and soil losses and reduce the amount of trees. Therefore, if these behaviors are not under supervision in the process of development, the environment that people live upon will be irreversibly changed and people's health being and social order will be influenced.

\section{Environment will Influence the Economy}

In recent years, the change of environment influences residents' life. China has serious air pollution and smog problem is the most serious one. At the end of 2016, Xi'an city initiated emergency response to heavy air pollution which would ease the pollution but still cause bad consequences, such as the rapidly increase of patients with respiratory tract infection and impediment of agricultural crops. It can be seen that environmental changes will hinder economic growth and go against sustainable development.

\section{Exercise the Regulating Role of Market Economy}

When solve the environmental problems, we should fully exert market mechanism to regulate economy and exercise its role in resources allocation. The enterprises in Shaanxi should set good examples, avoiding pursuing short-term profit at the cost of environment. Also, we should proactively promote the transformation of corporates, develop new industries, follow the path of green, scientific and sharing development and shoulder social responsibility. Thus, in developing Shaanxi's economy in a sustainable way, enterprises should participate in the development and exert their functions, protect the environment and build a good living world.

\section{References}

[1] Xueyuan Tian. Sustainable development of population and environment[J]. South China Population, 1996(1):3-9.

[2] Zhilei Li. Research on problems in sustainable development of economy and environment in Shaanxi[D]. Northwest University, 2011.

[3] Min Song, Xuemin Liu. A prospective study of energy-environment-economy sustainability in the Northwest region-taking Shaanxi Province as an example[J]. Chinese Population: Resources and Environment, 2012, 22(5):133-138.

[4] Min Zheng. Strategies on sustainable development in Shaanxi Province under the context of ecological environment restrict [J]. Jiangsu Business, 2013(14):80-80.

[5] Deyi Zheng. An analysis on "protecting ecological environment is developing productivity" a study on relationship between ecological environment and economic sustainable development[J]. Shaanxi Environment, 1999(3):1-5. 